ARTICLE

https://doi.org/10.1057/s41599-019-0310-1

\title{
Creating and communicating social research for policymakers in government
}

\author{
Jessica H. Phoenix (iD) ${ }^{1}$, Lucy G. Atkinson ${ }^{1}$ \& Hannah Baker (iD ${ }^{1}$
}

\begin{abstract}
Many academics ask 'How can I use my research to influence policy?'. In this paper, we draw on our first-hand experience as social researchers for the British Government to advise how academics can create and communicate research with policymakers. Specifically, we describe methods of communicating research to policymakers in relation to research we undertook to listen to farmers about their priorities for a new agricultural policy for England following the exit of the UK from the European Union. The main purpose of this research was to ensure farmers' voices were included in policy development and therefore communication of the research to policymakers was key. We reflect on the effectiveness of the communication methods we employed and summarise our learnings into four practical recommendations: (1) make research relevant to policymakers; (2) invest time to develop and maintain relationships with policymakers; (3) utilise 'windows of opportunity'; and (4) adapt presentation and communication styles to the audience. We consider that employing these recommendations will help to improve how evidence is communicated between academia and government and therefore the influence of evidence in decision-making processes.
\end{abstract}

\footnotetext{
${ }^{1}$ UK Government, Department for Environment Food and Rural Affairs, London, UK. Correspondence and requests for materials should be addressed to J.H.P. (email: Jess.Phoenix@defra.gov.uk)
} 


\section{Introduction}

$1 / \mathrm{e}$ are employed as Government Social Researchers (GSR) and our day-to-day work revolves around communicating evidence to policymakers. We can be understood as 'knowledge brokers' as we "effectively construct a bridge between the research and policy communities" (Nutley et al., 2007, p. 63). Therefore, the practices we employ can be of use to academics who want to share their research with policymakers. Against the background of limited empirical evidence regarding how academics can create impact on policy (Oliver and Cairney, 2019), the sharing of our day-to-day work provides important tangible experiences and recommendations for how academics can effectively engage with policymakers. In this paper we draw on our experiences to offer practical recommendations for how academics can engage with policymakers to ensure policy making is evidence-informed (Mayne et al., 2018), and consequently to improve policy effectiveness and programme efficiency (UK Government, 2013).

In this paper we first outline our role as knowledge brokers and critique the concept of the 'two communities' of policy and academia. We then introduce the policy backdrop to our research; future farming policy in the context of EU Exit. We briefly describe an in-house social research project that we undertook to gauge farmers' views of future farming policy in the context of EU Exit. Subsequently, we describe our methods of communicating the research findings from this project, based upon dialogue and argumentation (Sanderson, 2009), with policymakers by involving policymakers early on in the process, inviting policymakers to be directly involved in the research, regularly sharing findings and presenting the findings in simple formats such as posters and slidedecks. Finally, we share key learnings from our work to offer recommendations to academics about effective strategies to both create and communicate research with policymakers.

Rather than providing a full account of the evidence/policy literature (which is covered by Oliver and Cairney, 2019; Evans and Cvitanovic, 2018; Cairney and Kwiatkowski, 2017; Witting, 2017), we show how we are making sense of such studies in our day-to-day work. We focus on situating ourselves in the evidence/ policy environment and clearly communicating our research. A key advantage of this paper is that recommendations are made as to how to communicate evidence with policymakers based on our first-hand experience. Furthermore, we write in a manner that puts some of these recommendations into practice.

\section{Government social researchers as 'knowledge brokers'}

GSR share evidence with policymakers to ensure policy is evidence-informed. To do this effectively, we first understand the policy issue being worked on, co-design the questions being asked, and attempt to collaboratively answer these questions with suitable evidence. Collecting evidence involves commissioning research, searching for relevant academic literature, undertaking evidence reviews on policy relevant topics and delivering in-house research. Evidence needs to be suitable to the needs of the policymakers and reworked dependent on the question being asked. We often streamline, condense and target the evidence to make it relevant to the policy questions being asked, and to make it more understandable. The number of GSR in UK Government has substantially increased in recent years due to the need for evidence to inform policy developments in regard to EU Exit. The employment of evidence professionals means that, in opposition to Newman et al. (2016) findings about the Australian government, the British Government now has increased capacity to engage with diverse forms of evidence.

Despite being positioned at the interface of research and policy making, the work of GSR is not routinely recognised as academic, and we are overlooked in literature regarding the binary construct of the 'two communities' of policy and academia/research-producers (Caplan, 1979; Dunn, 1980; and Slavin, 2002). The 'two communities' construct is widely used "to describe the disconnect between the worlds of academia and policy" (Newman et al., 2015, p. 24). Academia is conceptualised to be "preoccupied with abstract concepts and theoretical explanations" (Newman and Head, 2015, p. 384) whilst policymakers are "faced with real-life problems that needed to be resolved in real time" (Newman and Head, 2015, p. 384). Hence, the construct relies on identifying gaps between policy and academia and assumes that the two communities have a 'lack of fit' (Wehrens, 2014). Furthermore, Topp et al. (2018) suggests that the problems identified in the 'lack of fit' between the two communities exist even when the two communities belong to the same organisation and are located in the same building.

We contend that the two communities construct problematically assumes heterogeneity between the communities and homogeneity within these communities (Wehrens, 2014). Newman (2014) troubles the assumed heterogeneity in the two communities' construct in his research with Australian public servants. Newman (2014, p. 614) writes that:

public servants who claim to use academic research in their policy work are more likely to have much in common with academics, including having postgraduate degrees and work experience in the university sector.

We strongly relate to Newman's challenge of this construct. We are employed by the British Government as Civil Servants on the basis of having specialist skills and knowledge of social research. Hence, if we take the 'two communities' construct to be true, we sit as knowledge brokers at the interface between the two (Nutley et al., 2007); we are in the policy community and we are producers of research. As a point of comparison, Table 1 displays the key problems identified in the disconnect between the two communities and how they apply or do not apply to GSR.

Table 1 shows that not all of the problems posed by the disconnect between academics and policymakers apply to GSR and policymakers, in large part because of our role as knowledge brokers. Although differences exist between GSR' and academics' relationship with policymakers, we have valuable 'insider' insight into the policy process, creation of evidence and evidence dissemination that scholars recognise to be critical for academia to understand (Monaghan, 2011; Mayne et al., 2018; and Cooper, 2016).

We recognise that our role as GSR gives us direct access to policymakers, unlike many academics, and therefore some of the research communication methods that we describe in this paper may be difficult for academics to implement. Consequently, we split the paper into two. The first half of the paper is written to help academic knowledge brokers further develop their understanding of policymakers, and how GSR knowledge brokers create and communicate research with policymakers. The second half of the paper distils our experience into practical recommendations for academics that want to improve their engagement with policymakers and increase the likelihood that their evidence impacts policymaking. We draw on our close relationship with policy to aid academics in their communication of evidence to policymakers, with the aim of further developing evidence-based policy.

\section{Farming and EU exit policy environment}

We work in a central evidence team for the Future Farming and Countryside Programme in the Department for Environment, Food and Rural Affairs (Defra). This Programme is composed of 
Table 1 Key problems posed by the disconnect between the two communities of policymakers and academia (Cairney, 2016, pp. 89-92) Key problems posed by the
disconnect between the two communities

Language barriers

Timescales

Incentives

Perceptions of scientific knowledge

Policymakers are looking for certainty and clear solutions

Scientists focus on 'the evidence', policymakers try to reconcile beliefs

\section{Application of problems to academics and policymakers}

Application of problems to GSR and policymakers

The primary audience of GSR research is policymakers so GSR translate research into simple, concise, tailored and accessible policy language

GSR examine issues over the short and long term and share findings when required by policymakers and when policymakers are likely to take note of the evidence. GSR are required to be reactive to policymakers evidence needs and deal with fast paced and changing timescales during research because of policy changes. GSR build robust inhouse evidence bases so information can be easily and quickly extracted for policymakers

Unlike scientists, the primary incentive is for GSR to communicate research with policymakers when it is required. Research is communicated with policymakers before the research is published on Government websites and/or in journals

Unlike scientists, GSR do not value their research by journal impact and funding. Instead, the value of research is assessed according to its impact in decision making information, and often recognise the importance of other forms of knowledge, such as community and cultural knowledge'... Policymakers do not share scientists' adherence to journal impact and funding as key metrics" (Cairney, 2016, pp. 89-92)

"For a major change in policy, ministers want 'proof', but scientists offer the 'balance of probabilities'... The 'contested and uncertain' nature of much information makes it unsuitable for policymakers" (Cairney, 2016, p. 92)

“Policymakers 'expect evidence-based analysis' but 'have to make judgments that balance different opinions, as well as claims and counterclaims from interest groups, including scientists'" (Cairney, 2016, p. 92)

Like scientists, GSR communicate the balance of probabilities. GSR also make recommendations on the robustness of the evidence and how it should be used to inform policy making

Like scientists, GSR provide policymakers with evidence to enable policymakers to reconcile beliefs and challenge their assumptions

Application of these problems to academics and policymakers, and to GSR and policymakers

multiple policy teams, from Environmental Land Management, to Regulation and Enforcement, to Animal and Plant Health. We collate, create and communicate evidence to policymakers in these policy teams to inform policy development. In this paper, we use the term 'policymakers' to refer to colleagues in Defra who are involved and responsible for the development of farming policy (Lexico, 2019). All of these policy teams focus on issues related to EU Exit and farming, and aim to deliver a smooth agricultural transition away from the EU's Common Agricultural Policy and into a new approach to policy post EU Exit. EU Exit poses a significant change to policy and challenge to farmers. It is a high profile policy area and Ministers are motivated to create new, and different, policies. It is therefore a high priority work area for the Programme.

Farmers are one of the most important stakeholder groups in the development of this future policy; they manage $70 \%$ of the land in England (Defra, 2018) and their management decisions are crucial to the achievement of policy outcomes. We therefore recognised the need to understand their viewpoints on, and experience of, agricultural policy to inform new policies for the countryside that deliver successful outcomes for the public and farmers. In light of this need, we undertook a research project to understand farmers' opinions and ideas for future agricultural policy post EU Exit, and to communicate these opinions with policymakers. Our aims for the delivery of the research project were to ensure the research could evolve in the changing policy environment, to communicate the findings to policy teams and ensure policy teams were invested in the pertinence of future social research.

\section{Methodology for farmer discussions}

The complex and dynamic environment of EU Exit required a research approach that was reactive to policy changes and enabled stakeholder insights to be shared with policymakers at pace, hence we undertook the project in-house.

Farmers were initially invited to be involved in this research via Twitter in August 2017. Moreover, leaflets detailing information about the research and our team's contact details were given to farmers at an existing Defra project meeting. This led to informal snowball recruitment through farming networks which enabled us to understand the viewpoints of 'hard to reach' farmers with whom Defra do not normally converse.

The research consisted of unstructured discussions (Fontana, 2007; and Morgan, 1997) with farmer groups across England to collect farmers' views on future policy. Discussion participants were self-selecting and groups ranged from less than 10 participants to over 30. Farmers and catchment advisors hosted the discussions and invited other attendees, including their farming neighbours and existing discussion groups. Discussions were held across England (Fig. 1) with farmers from all farm sectors between October 2017 and June 2018. We did not aim to gather views that were representative of the English farming population, 


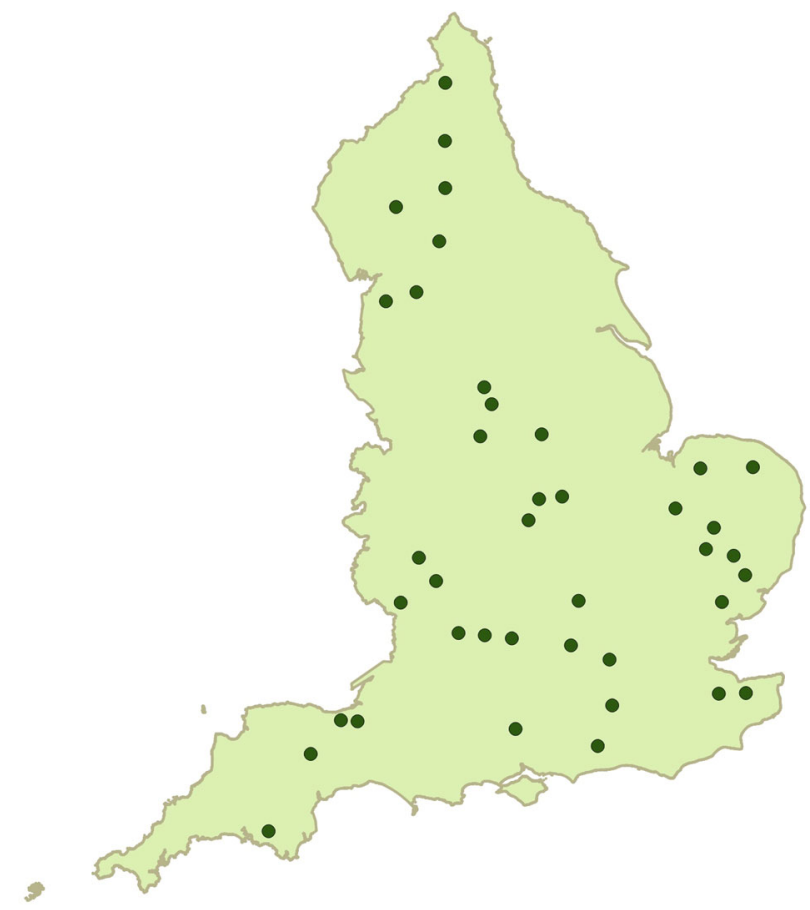

Fig. 1 Locations of 40 farmer discussions. These discussions took place between October 2017 and June 2018

but rather aimed to listen to the diversity of views in different farming sectors (e.g., livestock, cropping) and different geographies (e.g., hill farming, peri-urban, rural). 'Farmers' is used throughout this article as shorthand for all discussion participants.

Participants discussed issues most pertinent to them, giving their personal context to issues. The unstructured discussions lasted 2 to 4 hours. Usually, at least one government social researcher and one policymaker attended each discussion. Notes taken at the discussions were typed up into summaries as soon as possible after the discussion. Nearing the end of the research project in June 2018, the summaries were compiled and subject to thematic analysis. The findings were organised into three themes, with five issues in each theme (Defra and Government Social Research (2018) Farmers voices, government listening. [Unpublished]).

\section{Methodology for evidence communication with policymakers} As GSR in a centralised evidence team, we were the 'face' of this research project. The close association between ourselves and the research helped us to build personal working relationships with policymakers. Four GSR (three female and one male) were involved in the evidence communication strategy, ranging in seniority and experience. The most senior member of the team had worked in Government for over 15 years and therefore had extensive experience of evidence communication to policy teams. The communication methods detailed in this paper were informed by his experience. Another member of the team was both a social researcher in government and a social researcher in academia, hence concurrently sat in and between the "two communities" (Caplan, 1979; and Dunn, 1980). Her seminar teaching experience in academia informed the delivery of bitesize sessions (see below). All members of the team developed evidence communication methods through on-the-job training and experience.

We communicated the findings with roughly 400 colleagues (including approximately 250 policymakers, 60 evidence colleagues, 20 senior policy managers (hereafter referred to as senior management), 70 officers and advisors, and two ministers across the Defra group $\left.{ }^{1}\right)$. We involved policymakers, senior management and a ministerial advisor in our research from its conception to ensure the work was collaborative and gained credibility. At first, some policymakers were hesitant of the research due to uncertainty regarding future policy direction and therefore uncertainty regarding the topics to be raised in the farmer discussions. However, promotion by senior management in Programme wide meetings gave credibility to the work and developed policy teams' interest. Consequently, policymakers attended the farmer discussions and became involved in the research. This aided our evidence communication strategy as policymakers recognised our specialism as GSR and therefore invested in the research. Our evidence communication strategy (Fig. 2) consisted of five methods:

1. Email to policymakers after each farmer discussion

2. Slidedecks

3. Discussions and presentations in bitesize sessions

4. Strategic discussions and presentations in meetings with senior management

5. Poster

We decided to communicate the evidence by sending emails to policymakers and hosting discussions (methods 1 and 3) at the beginning of the research project. However, the style of the communication changed as we developed relationships with policymakers and more effective engagement methods. We developed our communication methods based on evidence-based policy making literature, the effectiveness of the methods we implemented and our previous experience.

Following each farmer discussion, we drafted findings into email summaries which were sent to relevant evidence and policy colleagues and senior management in the Programme. These emails contained a brief introduction to the farming group, key findings from the farmer discussion and highlighted repeated themes from previous farmer discussions (Fig. 3).

Once the research was complete, we created slidedecks to present evidence to policymakers. We created both a short slidedeck containing high level findings for ease of access for senior management, and a slidedeck detailing the full findings (Defra and Government Social Research (2018) Farmers voices, government listening. [Unpublished]), which was shared with policy teams and attendees of the farmer discussions.

We also communicated our findings by delivering 30 and 60 minutes bitesize sessions to policymakers across the Programme and the Defra group (see footnote ${ }^{1}$ ). We presented 14 lunchtime sessions with 200 attendees, using the slidedecks described above. These included face-to-face bitesize sessions in three offices, as well as a series of webinars; webinars proved to be a useful tool for evidence dissemination across different offices. Each session was repeated at least twice in different locations in order to extend our engagement with Defra staff. We shared a summary of our research findings to highlight the rich qualitative evidence-base that we had available. We conducted two rounds of bitesize sessions with different target audiences. The first round provided general findings from across all the research themes to aid policy teams' to consider their work from a farmer's perspective. The second round provided tailored findings to specific policy teams.

Furthermore we undertook targeted engagement with senior management. We presented a summary of our findings to senior management, relevant to their policy area, and included specific examples and stories from farmer discussions.

At the end of the research project we designed a poster to display in Defra's main offices, which contained detail of the 


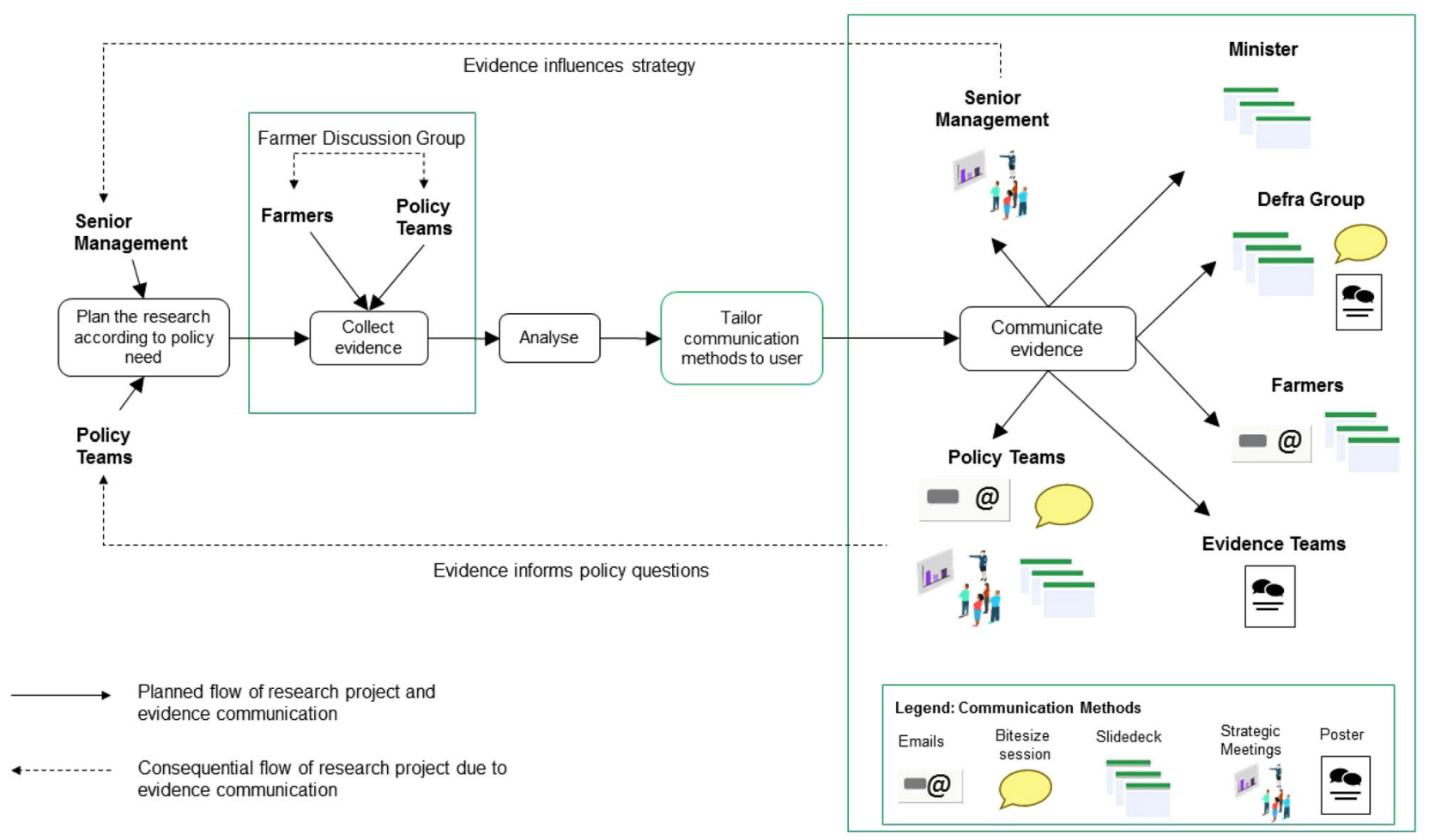

Fig. 2 Research process flow chart. The chart displays Government Social Researchers' evidence communication strategy and its associated impact ${ }^{1}$

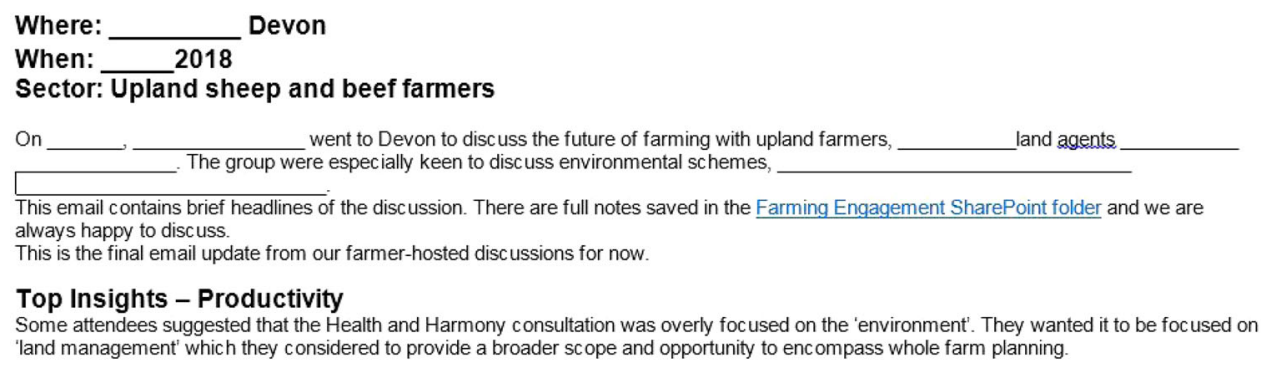

Fig. 3 Example format of summary emails. Identifiable information has been deleted

background, method, main findings and next steps for our research (Fig. 4). The poster enabled policymakers across the Defra group to quickly understand the main findings from the research.

\section{How did we increase the impact of the research project on policy development?}

Invite policymakers to take part in the research. Policymakers were invited to attend and be involved in the farmer discussions. This had a number of benefits. First, policy colleagues had a good grasp of the key issues they wanted to gauge farmers opinions' on. Evidence needs to be relevant to current policy needs (Head, 2010b), so inviting policymakers to discussions ensured that the research led to insights that were of a 'good fit' for their policy team. The use of unstructured focus groups allowed policymakers to ask specific policy-related questions where appropriate within the discussion. Second, leaving the office and meeting farmers gave policymakers time and space to think about their policy area in relation to the practicalities of farming. It enabled them to learn first-hand about farmers' challenges and ideas for future policy. Oliver and Duncan (2019) note that bringing together people with different perspectives allows learning from each other, and learning that is new to everyone involved. In light of this, we consider that bringing together policymakers and farmers encouraged policymakers to critically examine their policy ideas as farmers questioned and challenged current policy thinking. This led to new policy ideas being developed. Third, their involvement in discussions meant both policy and evidence colleagues collated personal tales from the research. As noted by Cairney and Oliver (2017), hearing the evidence through stakeholders' stories imbued emotion into the findings, thereby helping to prompt colleagues' attention to the importance of this work. Jones and Crow (2017) further note that the emotional aspects of a story are more likely to be remembered, therefore leading to a stronger ability to recall the information. For example, some GSR and policymakers told stories from this research project to other Defra colleagues about challenges faced by contract graziers; a type of farmer missing from Defra's database of farm holdings because they do not own or manage land. Therefore, these stories reflected the diversity of farmers who were otherwise hidden or unaccounted for in aggregated statistics. This approach also offered benefits to farmers, who by having direct conversations with policymakers, received immediate feedback from those 'using' the evidence and felt their 


\section{Farmers' Voices, Government Listening}

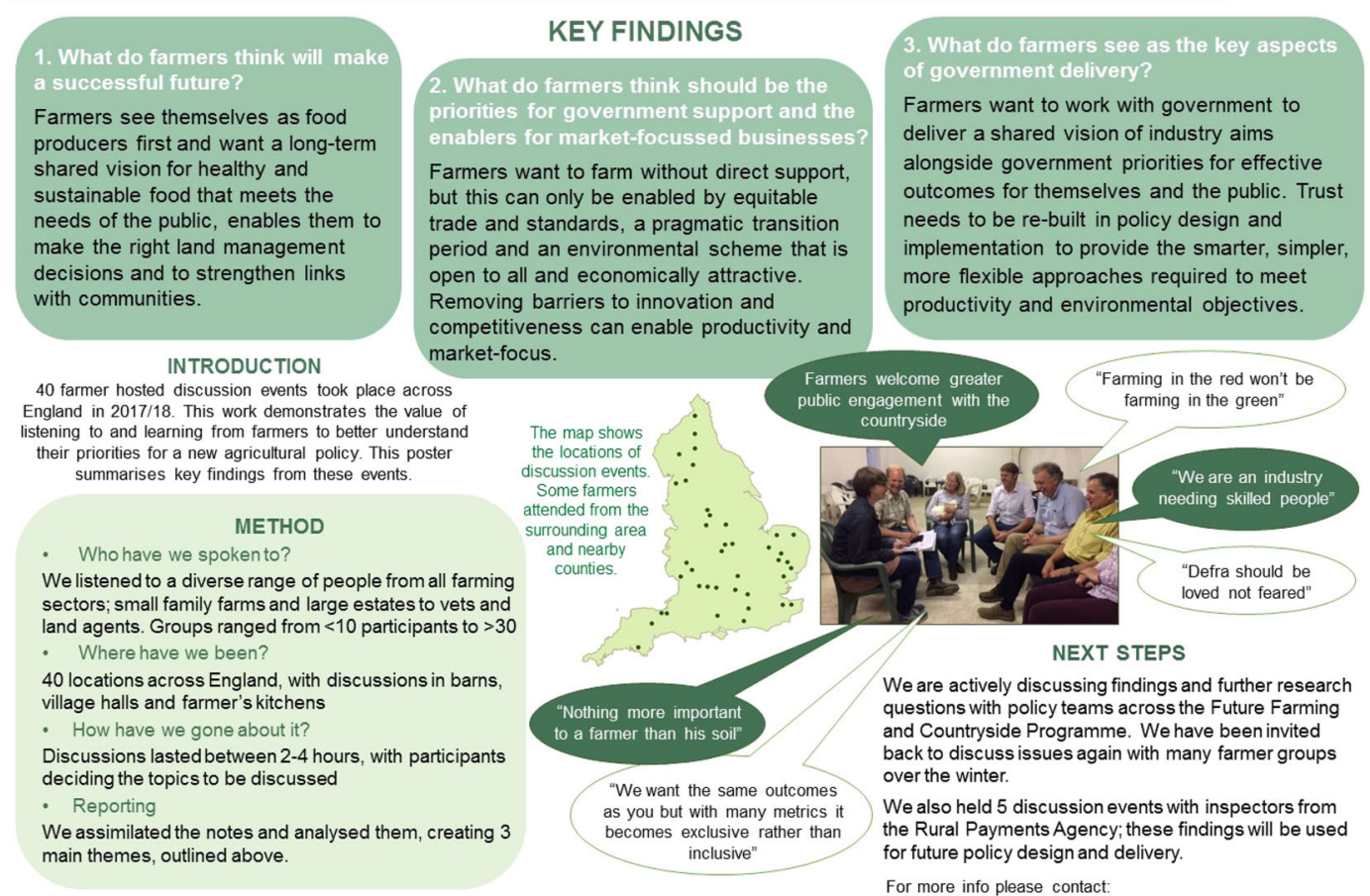

Fig. 4 'Farmers Voices, Government Listening' poster

views were being heard directly and in a salient manner. Fourth, colleagues who attended discussions became enveloped in the research and further interested in outputs from other discussions held around the country. This resulted in our continued engagement with policymakers about the findings. However, this approach was not without challenges. For example, we had to continuously engage with policy colleagues (using methods described throughout this paper) as they were busy and were themselves dealing with uncertainty in policy developments.

This constant iteration of the materials and format of the farmer discussions with policymakers provided policymakers with ownership over some of the findings.

Email after each discussion. At the beginning of the research project Future Farming policy post EU Exit was not clearly defined. In light of this ambiguity of future policies, emails sent to policymakers following farmer discussions highlighted farmers' views and ideas across a broad range of topics. The diversity of farmers' views presented in the emails challenged policymakers, contributed to their thinking and enabled them to pose further questions about policies. For example, farmers told us that 'productivity' is not a term that has resonance with them and they preferred the terms 'profitable' and 'competitive'. To share this finding effectively with policymakers, we emphasised that we were reporting 'what farmers' said' as opposed to fitting findings into pre-existing policy definitions.

As time passed, policy began to develop. We therefore fine-tuned our email approach so that research findings for particular topics were more strategically aimed at policymakers in order to increase their use (Farley-Ripple, 2012). For example, the key findings were reported in order of relevance to each policy area (Fig. 3), which enabled time-limited colleagues to easily access the evidence most pertinent to their policy work (Cairney and Kwiatkowski, 2017).
Presenting findings from each farmer discussion in specific emails provided each discussion group with a space and voice that was specific to their geography and circumstances. These 'microupdates' provided opportunity to highlight issues salient to farmers across policy areas and to translate complex evidence into simple stories (Cairney and Oliver, 2017). Storytelling is increasingly being recognised as an important dissemination tool in evidence-informed policy making in order to make simple messages persuasive (Cairney, 2016). Lock (2011) notes that just presenting evidence often does not persuade the audience to make a particular decision or action. Rather, Davidson (2017, p. 3) writes that evidence needs to be:

packaged or 'framed' in ways that connect to people's values and take account of the frames, worldviews or narratives in people's heads of how the world works

Our framing of farmer stories appealed to policymakers' emotions and therefore increased the resonance of our findings. The stories provided a "face" to anonymous facts (Davidson 2017, p. 7) and highlighted the diversity of views away from aggregate assumptions. We used stories to inform colleagues about how farmers' think policy ideas may play out in specific contexts and generated consideration from policymakers about the potential implications of their policies on farmers. Our story telling approach increased the attractiveness of the evidence and helped policymakers to remember the evidence (Jones and Crow, 2017). Stories help to engage people and first-hand examples personalise the evidence to increase resonance (Davidson, 2017). For example, the evidenced narratives we told were being recounted around the office six months later.

In addition, the regularity of the emails kept policy teams informed of the research project. We strategically sent emails to align with timings of policy developments. This increased the likelihood of our findings impacting policy because we identified 
suitable times to influence policy development. In other words, we took advantage of 'windows of opportunity' (Service et al., 2014; Cairney and Kwiatkowski, 2017; Head, 2010a; and Honig and Coburn, 2008). The uncertain timetable and evolving policy in relation to EU Exit meant policymakers' questions developed from week to week. The regular emails enabled policymakers to pose further questions they wanted us to ask farmers, which if relevant, we then posed to discussion groups.

The emails became a channel for discussion between and among policy teams, thereby extending the reach of the work. For example, a ministerial advisor regularly responded to these emails and generated regular further email discussion across a range of colleagues. These cross-team discussions led to the sharing of further evidence as colleagues fed in their own insights from other work.

Slidedecks. The principle communication method was a slidedeck (Defra and Government Social Research (2018) Farmers voices, government listening. [Unpublished]). Following on from the award-winning publication of the 'Future Farming and Environment Evidence Compendium' (Defra and Government Statistical Service, 2018), we created slidedecks in a similar manner to present the evidence to policymakers. Due to our inexperience in graphic design, we utilised the skills of a graphic designer to ensure the slidedecks were visually stimulating. Initially we created a short slidedeck containing high level findings for ease of access for senior management. This slidedeck was subsequently sent to Ministers, thereby extending the reach of social research to the highest level in Defra and raising the profile of social research in government. Successively, a slidedeck detailing the full findings was created (Defra and Government Social Research (2018) Farmers voices, government listening. [Unpublished]). This was shared with policy teams and attendees of the farmer discussions. In comparison to an academic paper the slidedeck was more concise and easier for policy teams to dip in and out of at their ease, hence increased accessibility of the evidence.

Bitesize sessions. We also communicated the research findings in informal lunchtime bitesize sessions. We encouraged people to bring their lunch to the bitesize sessions in order to create an informal atmosphere. This informality provided a 'safe space' for policymakers to ask questions that they may not otherwise ask in a more formal setting. This resonates with the work of Mawhinney (2010) who noted that teachers use school lunch times to have informal conversations and share professional knowledge with one another, thereby building trust between colleagues.

We undertook 'guess the finding' (Rothstein, 2016) in all bitesize sessions. This involved asking attendees a multi-choice question related to our research, recording their answers, and then presenting the answer from our findings, for example:

Question-What did farmers think needs to change for future delivery of government-led schemes?

Answer 1-Forward contracts and price certainty

Answer 2-Certainty about the future support they will get

Answer 3-Confidence in return on investment

Answer 4-A good income in the first place-they need to be profitable in order to invest

The approach engaged attendees in the session and encouraged them to consider policy from farmers' perspectives. There is a tendency for policymakers to focus on their own ideas or perceptions when developing policy, and for these ideas to be reinforced by the evidence they read and their team in 'groupthink' (Hallsworth et al., 2018). Like Louis XIV and his hall of mirrors in the Palace of Versailles, Rose (1999) poses that we, as researchers, are susceptible to seeing what we want reflected back to us. In a similar manner, we found that policymakers also have a hall of mirrors. The rapidity of change of EU Exit and associated policies made it difficult for policymakers to keep fully up to date with stakeholder opinions and evidence, and therefore their hall of mirrors could stand unchallenged. Our findings provided a snapshot of farmers' viewpoints and stories which, to many colleagues, was a new insight to add to their existing evidence portfolio and to their understanding. Our approach therefore challenged some colleague's assumptions and perceptions about farmers by temporarily removing them from their hall of mirrors. This helped to build up both GSR and policy colleagues' understanding of the evidence, which Head (2010b) states is crucial for evidence-informed policy.

The bitesize sessions generated further interest in the research and requests for more sessions to reach other policymakers. Reflective of Walter et al. (2003) our tailoring of evidence to policy teams led to in-depth, active discussions which improved the likelihood of the evidence informing policy development. We utilised these sessions to ask policymakers how else we might effectively communicate our findings with their teams and were subsequently invited to policy specific events, such as away days. However, some sessions were difficult to facilitate because policy teams were prone to talking about issues beyond our findings. We worked hard to bring the discussion back to the topic at hand and provided a digital copy of the slidedeck for policymakers' reference after the bitesize session to ensure they could contact us with any follow up questions.

These bitesize sessions facilitated the establishment of multiple networks between ourselves and the policy teams. These networks helped us to understand the constraints within which policy teams operate, the motivations and influences of policy colleagues besides research evidence, and in turn the values associated with different evidence sources that we present to them (Cairney et al., 2016; and Head, 2010b). In summary, the bitesize sessions helped us to develop trusted and long-term relationships with policy teams, which improved our influence and engagement in the policy making process.

Strategic meetings with senior management. We held seven meetings with senior management personnel who were responsible for entire policy areas and teams. We introduced ourselves as their policy team's 'go-to' GSR and asked about their evidence gaps. This opened up further opportunities to share our findings more widely. For example, one senior manager provided the following feedback and request:

"I found last week's briefing on the farmer engagement events really useful. I was wondering if you could repeat this for the colleagues in my team?"

The discussions enabled us to develop a strategic focus for our work and our priorities for social research moving forward. We fostered relations through sincere, direct engagement which built trust, raised our personal profiles and the profile of evidence. This approach helped to disseminate evidence during a period of policy changes and uncertainty, which Head (2010b) states is a difficult time for evidence-informed policy to operate. We used this engagement to contribute farmers' voices to the policy discussions and highlighted areas where evidence was missing from the policy making process, including where evidence was in 
conflict with policy colleagues' thinking. Senior management recognised that they needed to be aware of the evidence, understand its strengths and limitations, and reconcile this with the wider policy context. The meetings ensured evidence could be balanced with other competing perspectives in the "fuzzy, political and conflictual” policy process (Head, 2010b, p. 83). It was beneficial to attend these meetings in person because we were able to improvise our communication based on senior managements' body language (Opdenakker, 2006), provide more nuanced answers to questions, and create a more informal setting for discussing the research.

Inevitably senior management raised connections between their team's work and other policy areas in the Defra group. This enabled the identification of any overlap or potential clashes with other policy areas. It brought policy teams closer together and helped different policy teams to consider cross cutting issues. This shows how periods of policy complexity can provide opportunities for evidence to be used and to overcome siloed ways of working (Head, 2010b).

These strategic meetings with senior management involved more time investment than other engagement methods, but ensured farmer's voices were heard by people involved at all levels of policy development.

Poster. The creation of posters provided a space to convert qualitative findings into eye-catching information. Evidence suggests that using a variety of dissemination methods can improve knowledge transfer, engagement with the research and in turn its impact (Walter et al., 2003; Llic and Rowe, 2013; and Witting, 2017). In particular, Llic and Rowe (2013) state that posters provide a concise overview of research findings which can stimulate informal discussion. We used the poster to rouse interest in the research project and encourage evidence teams to contact us for more information.
We sent the poster to evidence colleagues across the Defra Group via an online newsletter and displayed it in Defra offices across England. Sharing the poster with evidence colleagues created further requests for information about our research. For example, requests for a fuller report of the findings, requests to extract tailored evidence for specific evidence teams, and requests to deliver bitesize sessions for different policy teams. The poster improved the 'poor fit' (Head, 2010b) between how evidence is assembled by researchers and the practical needs of policy colleagues. We consider that evidence needs to be packaged and communicated in a well written, targeted, and accessible way because even robust and reliable research is not always utilised in policy making.

\section{Recommendations for evidence communication with policymakers}

We have themed recommendations arising from our experience of communicating and creating evidence from the research project described. A summary of recommendations is shown in Box 1.

Make the research relevant to policymakers. Of course, evidence should be appropriate to policy needs (Parkhurst, 2017). Parkhurst (2017) notes that evidence is appropriate if it addresses the key policy concerns at hand, is applicable to the local context and is constructed in ways useful to address policy concerns. To determine the appropriateness of evidence and-if desired-to make evidence more appropriate to policy, we encourage academics to network and engage with policymakers prior to beginning the research. We recommend involving policymakers early on in the research to establish commitment, provide context to policy development and to put a face to the evidence (Davidson, 2017). Commitment can be furthered by inviting policymakers to be involved in the research, if collection methods

\section{Box 1: Relevant learnngs from our work for academics who are trying to communicate their research to policymakers}

\section{Make the research relevant to policymakers}

- Involve policymakers early on in the research process and invite them to shape the research, for example defining policy questions for interviews and focus groups.

- Be prepared to adapt a presentation to the situation depending on questions or comments made by policymakers. A bank of relevant stories specific to the policy area may help academics to respond to questions with memorable answers.

- Have flexibility in methods to increase the attractiveness and relevance of research to policymakers.

\section{Invest time to develop and maintain relationships with policymakers}

- Use relationships with policymakers to map out the policy landscape in order to quickly target communications to relevant civil servants; Government Social Researchers can potentially help academics to navigate the policy landscape. Ask senior management about the most appropriate engagement methods for their specific policy teams.

- Network and engage with policymakers prior to beginning research to establish links and demonstrate how the research is of use for policy.

Utilise 'windows of opportunity'

- Find opportunities to regularly present research to policymakers, using tailored stories to present evidence from a specific voice and context.

- Group research findings into policy specific themes so these are ready to disseminate quickly on request.

- Provide regular updates to senior management and offer help when 'windows of opportunities' are identified.

\section{Adapt presentation and communication styles to the audience}

- Summarise the research in a visually attractive format, with a variety of information such as repeated themes, quotes and key insights.

- Use a consistent template and adapt presentations to the policy area.

- Use different communication methods and types to extend the reach of the research, such as round-table discussions in face-to-face presentations, and a 'Question and Answer' format for online webinars. Interactive approaches such as 'guess the finding' can engage policymakers and find out what their assumptions and opinions are.

- Provide a digital copy of the presentation including contact details for any follow up.

- Allow plenty of time for discussion of the research when organising presentations.

- Use engaging publication methods to share findings with policymakers. We suggest using slidedecks and recommend involving a graphic designer in their creation. 
and ethics allow. Academics can further allow policymakers to shape research by encouraging them to feed into methods, for example defining questions for interviews and/or focus groups. This will enable academics to establish links with the policy making process, demonstrate how the research can help to answer the key question(s) being asked and establish to whom their research is relevant (Evans and Cvitanovic, 2018).

Invest time to develop and maintain relationships with policymakers. We suggest academics invest time in creating and maintaining relationships with policymakers by providing regular updates to senior management and offering evidence when 'windows of opportunity' are identified (see below). It is a challenge to continuously engage with policymakers (using methods described throughout this paper) as they are busy and often deal with uncertainty in policy developments. However we consider it to be a necessary part of effective engagement.

In addition, we recommend academics find opportunities to regularly present research to policymakers so they become interested and invested in the work. When presenting information, use tailored stories to present evidence from a specific voice and context. The tailoring of research will help policymakers to recognise and remember pertinent points for their work. It is essential to adapt the presentations to the policy area. However, also be prepared to adapt to the situation depending on what questions or comments are made. It is beneficial to have a bank of relevant stories specific to the policy area so academics can respond to questions with memorable answers and enhance the richness of the discussion. We recommend that sessions are organised for 60 minutes to ensure there is enough time for academics and policymakers to have detailed conversations.

Utilise 'windows of opportunity'. We recommend that academics do not keep hold of evidence until it is finished and published, but rather communicate it with civil servants whenever it is relevant to a policy question. Taking advantage of 'windows of opportunity' increases the likelihood of evidence being considered in the policy making process. Periods of policy ambiguity, such as that created by EU Exit, present larger scope for decisions to be evidence-informed than matters which are tightly constrained by politics (Head, 2010a). Thus, it is important to be aware of topics that are of interest to policy to ensure evidence is timely.

Adapt presentation and communication styles to the audience. Multiple communication methods may need to be employed with different policymakers in different scenarios to meet their evidence needs, such as round-table discussions in face-to-face sessions, and a 'Question and Answer' format for online webinars. The use of multiple methods can develop an evidence-based dialogue between policymakers and therefore encourage the sharing of evidence. We suggest using interactive approaches such as 'guess the finding' to engage policymakers and uncover their assumptions and opinions. We recommend academics provide a digital copy of any presentations for the audience's reference, including contact details for any follow up.

In periods of policy ambiguity, civil servants are often stretched for time and will likely not invest time into reading a complex journal article. We recommend that instead of sending journal articles to policymakers, academics send a slidedeck or poster and offer to meet with the relevant policy team to share evidence faceto-face, for example in lunchtime sessions. These communication methods make it easier for policymakers to understand the evidence and help to form relationships between academics and the policy team. These relationships may be long lasting and lead to the co-production of evidence in the future.

\section{Summary}

This paper is based on a particular research project and therefore does not cover every possible method of communicating research with policy. We suggest that academics consider our recommendations, arising from first-hand experience, in light of those made by Oliver and Cairney's (2019) systematic review of 'how to' advice in the academic peer-reviewed and grey literatures. In addition to employing the communication methods described in this paper, we recommend more academics look to bridge the gap between the 'two communities' of academia and policy. For example, academics can undertake fellowships and/or secondments with government to learn about policy making and how to effectively share research with policymakers, therefore increasing the impact of their research. We are keen for more academics to provide commentary on their experiences of working with policymakers and for GSR to share 'lessons learned' with the aim of improving the links between academia and policy making.

We recognise that our recommendations take time and effort to implement, and do not always lead to the immediate results that may be desired. For example, policymakers may drop out of meetings at the last minute, it is difficult to establish commitment from policy teams, and academics may not have the flexibility to develop the research method as policy questions/problems develop. To increase the likelihood of evidence being considered in decision making, we recommend that academics draw on knowledge brokers to connect with policy-relevant knowledge networks and become aware of opportunities for new thinking. Knowledge brokers include academics working on research projects for government departments, individuals working in both government and academia, departmental social research expert groups (for example the Defra Social Science Expert Group ${ }^{2}$ ) and GSR. Academics can contact the Government Social Research profession (Government Social Research profession, 2019) and ask to be put in touch with GSR in the relevant field of work who can potentially help academics to navigate the policy landscape. Academics can then invite GSR and/or policymakers to be involved in their research from its inception and co-design research together. This will likely lead to the research being discussed by policy teams, develop civil servants' investment in the research and may increase the pertinence of the research in policy.

In summary, in this paper we have shared our practical experience of creating and communicating research with policymakers. For academics wanting to increase the utility of research for policy, we recommend to make the research relevant to policymakers, invest time to develop and maintain relationships with policymakers, utilise 'windows of opportunity', and adapt presentation and communication styles to the audience. We consider that employing these recommendations will help to improve how evidence is communicated between academia and government, and the influence of evidence in decision-making processes.

\section{Data availability}

The materials generated during and/or analysed during the current study are not currently publicly available, but are available from the corresponding author on reasonable request.

Received: 24 January 2019 Accepted: 5 August 2019

Published online: 27 August 2019

\section{Notes}

1 The Defra group includes: Defra; Natural England; the Environment Agency; the Animal, Plant and Health Agency; the Rural Payments Agency; the Forestry Commission; and the Veterinary Medicine Directorate.

2 The Social Science Expert Group is a sub-group of Defra's Science Advisory Council (Science Advisory Council, 2019). 


\section{References}

Cairney P (2016) The politics of evidence-based policy making. Palgrave Macmillan UK, London

Cairney P, Kwiatkowski R (2017) How to communicate effectively with policymakers: combine insights from psychology and policy studies. Pal Commun 3:37. https://doi.org/10.1057/s41599-017-0046-8

Cairney P, Oliver K (2017) Evidence-based policymaking is not like evidence-based medicine, so how far should you go to bridge the divide between evidence and policy? Health Res Policy Syst 15:35. https://doi.org/10.1186/s12961-017-0192-x

Cairney P, Oliver K, Wellstead A (2016) To bridge the divide between evidence and policy: reduce ambiguity as much as uncertainty. Pal Adm Rev 76 (3):399-402. https://doi.org/10.1111/puar.12555

Caplan N (1979) The two-communities theory and knowledge utilization. Am Behav Sci 22(3):459-470. https://doi.org/10.1177/000276427902200308

Cooper ACG (2016) Exploring the scope of science advice: social sciences in the UK government. Pal Commun 2:16044. https://doi.org/10.1057/palcomms.2016.44

Davidson B (2017) Storytelling and evidence-based policy: lessons from the grey literature. Pal Commun 3:17093. https://doi.org/10.1057/palcomms.2017.93

Defra (2018) Health and Harmony: the future for food, farming and the environment in a Green Brexit-policy statement. Department for Environment Food and Rural Affairs. https://www.gov.uk/government/publications/thefuture-for-food-farming-and-the-environment-policy-statement-2018/ health-and-harmony-the-future-for-food-farming-and-the-environment-ina-green-brexit-policy-statement. Accessed 17 Jan 2019

Defra and Government Statistical Service (2018) The Future Farming and Environment Evidence Compendium. Department for Environment Food and Rural Affairs. https://assets.publishing.service.gov.uk/government/uploads/ system/uploads/attachment_data/file/683972/future-farming-environmentevidence.pdf. Accessed 17 Jan 2019

Dunn W (1980) The two-communities metaphor and models of knowledge use: an exploratory case survey. Sci Commun 1(4):515-536. https://doi.org/10.1177/ 107554708000100403

Evans MC, Cvitanovic C (2018) An Introduction to achieving policy impact for early career researchers. Palgrave Commun 4:88. https://doi.org/10.1057/ s41599-018-0144-2

Farley-Ripple L (2012) Research use in school district central office decision making: a case study. Educ Manag Adm Leadersh 40(6):786-806. https://doi. org/10.1177/1741143212456912

Fontana A (2007) Interviewing, structured, unstructured, and postmodern. The Blackwell Encyclopaedia of Sociology. https://doi.org/10.1002/97814051655 18.wbeosi070. Accessed 17 Jan 2019

Government Social Research profession (2019) Government Social Research profession. https://www.gov.uk/government/organisations/civil-service-governmentsocial-research-profession. Accessed 26 June 2019

Hallsworth M, Egan M, Rutter J, McCrae J (2018) Behavioural Government: using behavioural science to improve how governments make decisions. The Behavioural Insights Team. https://www.behaviouralinsights.co.uk/publications/ behavioural-government/. Accessed 17 Jan 2019

Head B (2010a) Evidence-based policy: principles and requirements. In: Australian Government Productivity Commission (ed). Productivity Commission (2010) Strengthening evidence-based policy in the Australian Federation, 1, Roundtable Proceedings, Productivity Commission, Canberra, Australia, pp. 13-26

Head B (2010b) Reconsidering evidence-based policy: key issues and challenges. Policy Soc 29(2):77-94. https://doi.org/10.1016/j.polsoc.2010.03.001

Honig M, Coburn C (2008) Evidence-based decision making in school district central offices. Educ Policy 22(4):578-608. https://doi.org/10.1177/089590480 7307067

Jones MD, Crow A (2017) How can we use the 'science of stories' to produce persuasive scientific stories? Palgrave Commun 3:53. https://doi.org/10.1057/ s41599-017-0047-7

Lexico (2019) Lexico: dictionary. https://www.lexico.com/en/definition/policymaker. Accessed 28 June 2019

Llic D, Rowe N (2013) What is the evidence that poster presentations are effective in promoting knowledge transfer? A state of the art review. Health Inf Libr J 30(1):4-12. https://doi.org/10.1111/hir.12015

Lock SJ (2011) Deficits and dialogues: science communication and the public understanding of science in the UK. In: Bennett DJ, Jennings RC (eds) Successful science communication. Cambridge University Press, Cambridge, p $17-30$

Mawhinney L (2010) Let's lunch and learn: professional knowledge sharing in teachers' lounges and other congregational spaces. Teach Teach Educ 26 (4):972-978. https://doi.org/10.1177/0192636515602330

Mayne R, Green D, Gujit I, Walsh M, English R, Cairney P (2018) Using evidence to influence policy: Oxfam's experience. Pal Commun 3:122. https://doi.org/ 10.1057/s41599-018-0176-7

Monaghan M (2011) Evidence versus politics: exploiting research in UK drug policy making? The Policy Press, Bristol
Morgan D (1997) The focus group guidebook. Sage Publications, London

Newman J (2014) Revisiting the "two communities" metaphor of research utilisation. Int J Public Sect Manag 27(7):614-627. https://doi.org/10.1108/ IJPSM-04-2014-0056

Newman J, Head BW (2015) Beyond the two communities: a reply to Mead's "why government often ignores research". Policy Stud 48(3):383-393. https://doi org/10.1007/s11077-015-9226-9

Newman J, Cherney A, Head BW (2015) Do policy makers use academic research? Re-examining the "Two communities" theory of research utilisation. Public Adm Rev 76(1):24-32. https://doi.org/10.1111/puar.12464

Newman J, Cherney A, Head BW (2016) Policy capacity and evidence-based policy in the public service. Public Manag Rev 19(2):157-174. https://doi.org/ 10.1080/14719037.2016.1148191

Nutley S, Walter I, Davies H (2007) Using evidence: how research can inform public services. Policy Press, Bristol

Oliver K, Cairney P (2019) The dos and don'ts of influencing policy: a systematic review of advice to academics. Pal Commun 5:21. https://doi.org/10.1057/ s41599-019-0232-y

Oliver S, Duncan S (2019) Editorial: looking through the Johari window. Res All 3 (1):1-6. https://doi.org/10.18546/RFA.03.1.01

Opdenakker R (2006) Advantages and disadvantages of four interview techniques in qualitative research. Forum Qual Soz/Forum 7(4):11. https://doi.org/ $10.17169 /$ fqs-7.4.175

Parkhurst J (2017) The politics of evidence: from evidence-based policy to the good governance of evidence. Routledge, London

Rose DB (1999) Indigenous ecologies and an ethic of connection. In: Low N (ed) Global ethics and environment. Routledge, London, p 175-187

Rothstein T (2016) 3 workshop ideas for sharing your research findings. https:// medium.com/@tessrothstein/make-your-findings-interactive-d83a2204b11e. Accessed 17 Jan 2019

Sanderson I (2009) Intelligent policy making for a complex world: pragmatism, evidence and learning. Political Stud 57(4):699-719. https://doi.org/10.1111/ j.1467-9248.2009.00791.x

Science Advisory Council (2019) Science advisory council. science advisory council. https://www.gov.uk/government/organisations/science-advisory-council. Accessed 26 June 2019

Service O, Hallsworth M, Halpern D, Algate F, Gallagher R, Nguyen S, Ruda S, Sanders M, Pelenur M, Gyani A, Harper H Reinhard J, Kirkman E (2014) EAST: four simple ways to apply behavioural insights. https://www. behaviouralinsights.co.uk/wp-content/uploads/2015/07/BIT-PublicationEAST_FA_WEB.pdf. Accessed 17 Jan 2019

Slavin RE (2002) Evidence-based education policies: transforming educational practice and research. Educ Res 31(7):15-21. https://doi.org/10.3102/ 0013189X031007015

Topp L, Mair D, Smillie L, Cairney P (2018) Knowledge management for policy impact: the case of the European Commission's Joint Research Centre. Pal Commun 4:87. https://doi.org/10.1057/s41599-018-0143-3

UK Government (2013) What works: evidence centres for social policy. UK Cabinet Office, London

Walter I, Nutley S, Davies H (2003) Research impact: a cross sector review literature review. Part of a wider project entitled 'Models of Research Impact: a cross sector review', funded by the Learning and Skills Development Agency (LSDA). https://www.researchgate.net/profile/Huw_Davies5/publication/ 265218078 Research_Impact_A_Cross_Sector_Literature_Review/links/ 56013a2808aebald9f84f180.pdf. Accessed 17 Jan 2019

Wehrens R (2014) Beyond two communities-from research utilization and knowledge translation to co-production? Public Health 128(6):545-551. https://doi.org/10.1016/j.puhe.2014.02.004

Witting A (2017) Insights from 'policy learning' on how to enhance the use of evidence by policymakers. Pal Commun 3:49. https://doi.org/10.1057/s41599017-0052-x

\section{Acknowledgements}

We thank Tony Pike for establishing the research project on which this paper is based. Thanks to Jenny Kemp for designing and creating the slidedecks and the process chart shown in Fig. 2.

\section{Additional information}

Competing interests: The authors declare no competing interests.

Reprints and permission information is available online at http://www.nature.com/ reprints

Publisher's note: Springer Nature remains neutral with regard to jurisdictional claims in published maps and institutional affiliations. 
(c) (i) Open Access This article is licensed under a Creative Commons Attribution 4.0 International License, which permits use, sharing, adaptation, distribution and reproduction in any medium or format, as long as you give appropriate credit to the original author(s) and the source, provide a link to the Creative Commons license, and indicate if changes were made. The images or other third party material in this article are included in the article's Creative Commons license, unless indicated otherwise in a credit line to the material. If material is not included in the article's Creative Commons license and your intended use is not permitted by statutory regulation or exceeds the permitted use, you will need to obtain permission directly from the copyright holder. To view a copy of this license, visit http://creativecommons.org/ licenses/by/4.0/.

(c) Crown 2019 